\title{
MAARSY - the new MST radar on Andøya/Norway
}

\author{
R. Latteck, W. Singer, M. Rapp, and T. Renkwitz \\ Leibniz Institute of Atmospheric Physics at the Rostock University, Schloss-Str. 6, 18225 Kühlungsborn, Germany
}

\begin{abstract}
The Leibniz-Institute of Atmospheric Physics in Kühlungsborn, Germany (IAP) is installing a new powerful VHF radar on the North-Norwegian island Andøya $\left(69.30^{\circ} \mathrm{N}, 16.04^{\circ} \mathrm{E}\right)$ in 2009/2010. The new Middle Atmosphere Alomar Radar System (MAARSY) replaces the existing ALWIN radar which has been operated continuously on Andøya for more than 10 years. The new system is a monostatic radar operated at $53.5 \mathrm{MHz}$ with an active phased array antenna consisting of 433 Yagi antennas. The 3element Yagi antennas are arranged in an equilateral triangle grid forming a circular aperture of approximately $6300 \mathrm{~m}^{2}$. Each individual antenna is connected to its own transceiver with independent phase control and a scalable output up to $2 \mathrm{~kW}$. This arrangement allows very high flexibility of beam forming and beam steering with a symmetric radar beam of a minimum half power beam width of $3.6^{\circ}$, a maximum directive gain of $33.5 \mathrm{~dB}$ and a total transmitted peak power of approximately $800 \mathrm{~kW}$. The IF signals of each 7 transceivers connected to each 7 antennas arranged in a hexagon are combined to 61 receiving channels. Selected channels or combinations of IF signals are sent to a 16-channel data acquisition system with $25 \mathrm{~m}$ sampling resolution and 16-bit digitization specified which will be upgraded to 64 channels in the final stage. The high flexibility of the new system allows classical Doppler beam swinging as well as experiments with simultaneously formed multiple beams and the use of modern interferometric applications for improved studies of the Arctic atmosphere from the troposphere up to the lower thermosphere with high spatiotemporal resolution.
\end{abstract}

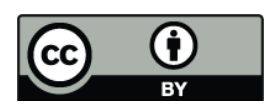

Correspondence to: R. Latteck (latteck@iap-kborn.de)

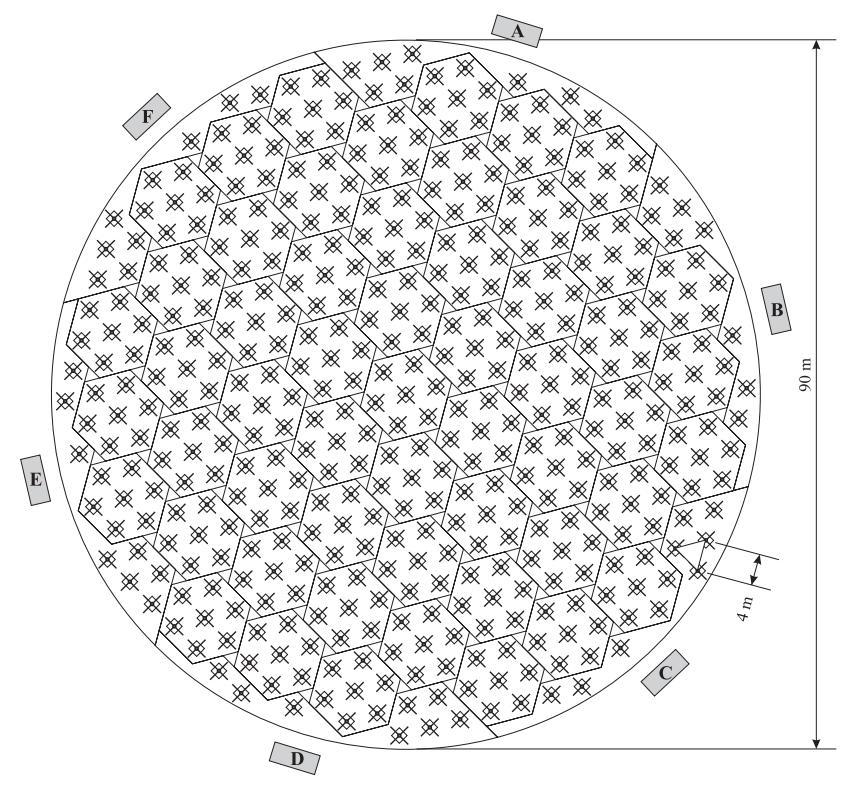

Fig. 1. Sketch of the antenna array of MAARSY. Each cross represents crossed three-element Yagi antennas mounted on a concrete block (small boxes). The six rectangles outside the array, indicated as A-F, represent containers accommodating the transmit-receive modules.

\section{Introduction}

In October 1998 the Leibniz-Institute of Atmospheric Physics in Kühlungsborn, Germany installed the ALWINVHF radar on the North-Norwegian island Andøya $\left(69.30^{\circ} \mathrm{N}, 16.04^{\circ} \mathrm{E}\right)$ as a successor to the former ALOMAR SOUSY radar (Singer et al., 1995). The ALWIN radar (Latteck et al., 1999) was designed for unattended and continuous observations of the tropo- and lower stratosphere but especially for observations of the mesosphere during summer time. The radar operated at a frequency of $53.5 \mathrm{MHz}$ with

Published by Copernicus Publications on behalf of the URSI Landesausschuss in der Bundesrepublik Deutschland e.V. 

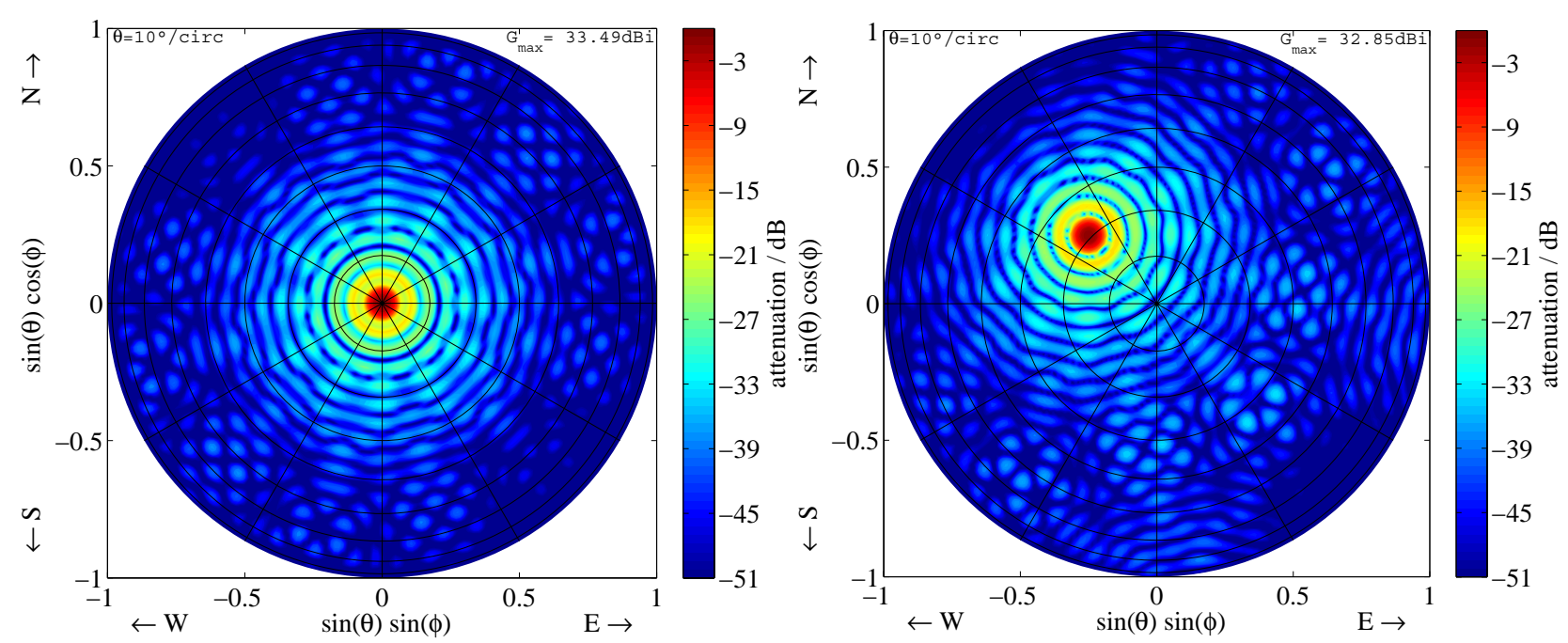

Fig. 2. Computed radiation pattern of MAARSY for an antenna beam pointed to zenith (left) and tilted to $21^{\circ}$ to the NW direction (right). The Numerical Electromagnetics Code (NEC) with the Norton-Sommerfeld approximation was used, making allowance for the imperfect ground at the location.

a peak power of $36 \mathrm{~kW}$ and a minimum range resolution of $150 \mathrm{~m}$. The antenna array consisted of 144 Yagi antennas arranged in 36 squared subsystems of four antennas. The system allowed operation in spaced antenna (SA) or in Doppler beam swinging (DBS) configuration with a $6.6^{\circ}$ radar beam (half power full width) but with a fixed number of beam directions.

After 10 years of nearly continuous operation the ALWIN radar was switched off in September 2008 to be replaced by a new, more powerful and more flexible radar. The major requirements for the new system are (i) classical DBS observation with improved temporal and spatial resolution and free beam steering capability, (ii) multiple beam observation, and (iii) multi-receiver and multi-frequency operation for modern interferometric applications.

The goal of the new system is the investigation of horizontal structures of Polar Mesosphere Summer Echoes (PMSE) caused by mesospheric ice clouds. Three-dimensional structures of the wind field and turbulent parameters determined from the radar data will be used to compare the detected PMSE distribution in detail with wind and turbulence variations caused by wave activity.

\section{System description}

The new Middle Atmosphere Alomar Radar System (MAARSY) on Andøya is a monostatic radar with an active phased array antenna. Its operational frequency is $53.5 \mathrm{MHz}$ and the maximum peak power is approximately $800 \mathrm{~kW}$. The system is composed of an active phased antenna consisting of 433 array elements and an identical number of transceiver
Table 1. Basic parameters of MAARSY. The statements in brackets indicate later upgrades.

\begin{tabular}{ll}
\hline Location & Andenes, Norway \\
& $69.30^{\circ} \mathrm{N}, 16.04^{\circ} \mathrm{E}$ \\
Operating Frequency & $53.5 \mathrm{MHz}$ \\
Peak power & $\sim 800 \mathrm{~kW}$ \\
Allocated bandwidth & $4 \mathrm{MHz}$ \\
Maximum duty cycle & $5 \%$ \\
Pulse length & $\geq 0.33 \mu \mathrm{s}$ \\
Sampling resolution & $25 \mathrm{~m}$ \\
Transmitted waveforms & Single pulse, Complementary code, \\
& Barker code \\
Pulse shapes & Square, Gaussian, Shaped Trapezoid \\
Antenna array & 433 three-element (crossed) Yagi \\
Effective antenna area & $\sim 6300 \mathrm{~m}^{2}$ \\
Half power beam width & $3.6^{\circ}$ \\
Directive gain & $33.5 \mathrm{dBi}$ \\
Beam directions & arbitrary zenith angles $<30^{\circ}$ \\
Receiving channels & $16(64)$ \\
\hline
\end{tabular}

modules. The basic parameters of the new VHF radar are given in Table 1.

The antenna array consists of 433 three-element linear polarized Yagi antennas designed by IAP. The antennas are arranged in a equilateral triangle grid structure with a spacing of $4 \mathrm{~m}(=0.71 \lambda)$. A sketch of the antenna array is shown in Fig. 1. The antennas are indicated by crosses, the small squares below the crosses represent the antenna footings made of massive concrete. In the first stage only the NW-SE oriented Yagi antennas will be mounted on the poles, the SW$\mathrm{NE}$ oriented antennas will be installed in the near future. The 


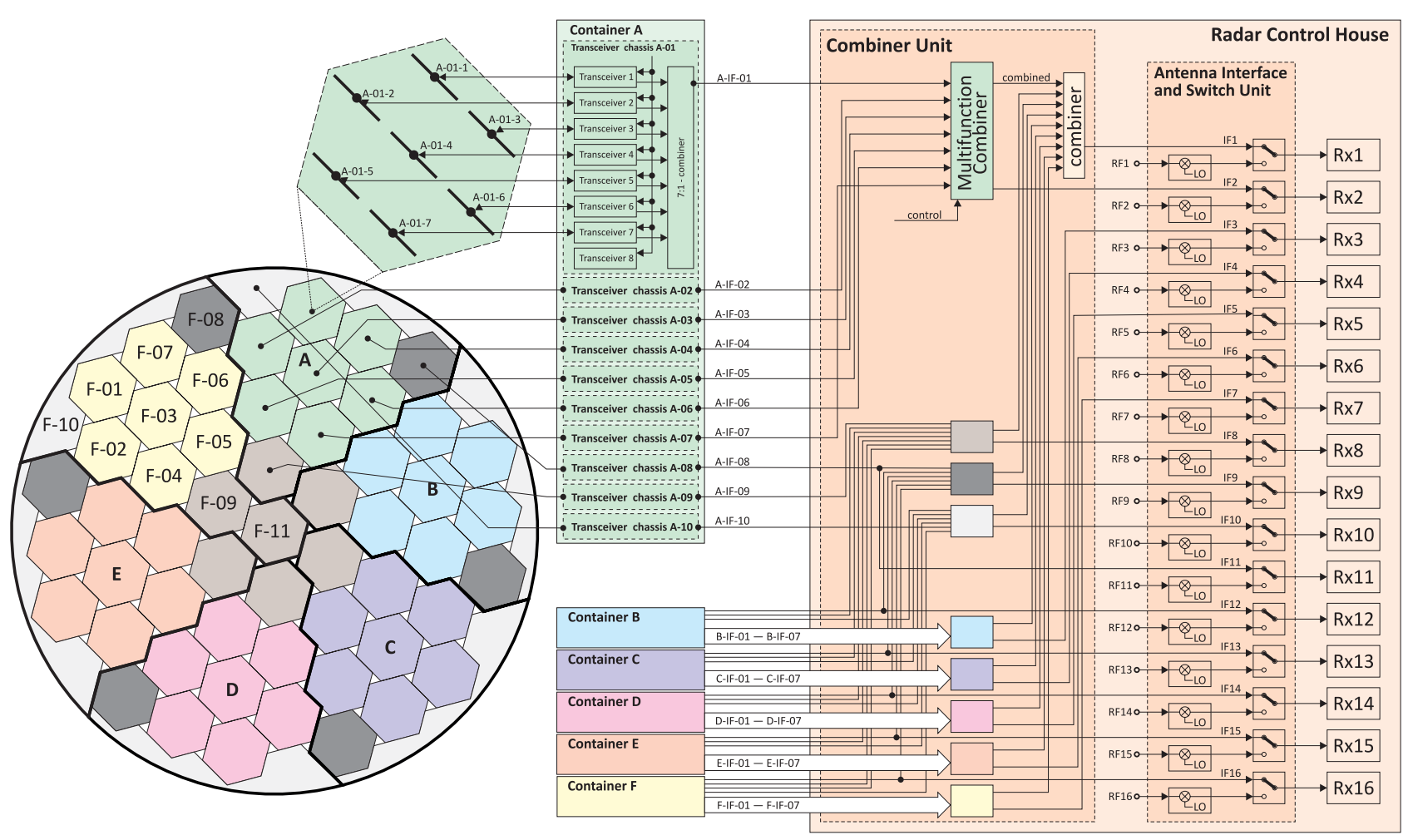

Fig. 3. Block diagram of MAARSY. Each antenna is connected to its own transceiver. The areas of the antenna array framed by thick lines and labeled as A-F represent the antennas connected to transceivers in the containers labeled respectively. On reception the IF signals from each of the 7 transceivers, each connected to 7 antennas arranged in a hexagon structure, and the IF signals from each of the 8 transceivers, each connected to 8 antennas located in asymmetric patches at the perimeter of the array, are combined to a total of 61 receiving channels. Controllable multifunction combiners are used to either combine the IF signals of 7 adjacent hexagonal antenna substructures or select one of them as input for the 16 base band converters.

nearly circular array with a diameter of approximately $90 \mathrm{~m}$ corresponding to an aperture of $\sim 6300 \mathrm{~m}^{2}$ results in a very symmetric antenna radiation pattern with a half power beam width of $3.6^{\circ}$, a directive gain of $33.5 \mathrm{dBi}$ and an almost symmetric first sidelobe with more than $17 \mathrm{~dB}$ suppression with respect to the main lobe. Figure 2 shows the computed radiation pattern of the new VHF radar antenna pointing to zenith and tilted to $21^{\circ}$ to the NW direction. The equilateral triangle grid structure of the array allows the beam steering down to an off-zenith angle of $30^{\circ}$ without grating lobes.

The antenna array is divided in 61 subarrays, 55 of them are identical hexagons consisting of 7 antennas each, 6 subgroups consisting of 8 antennas each are located at the perimeter of the array making it nearly circular. The theoretical beam width is approximately $30^{\circ}$ for a single hexagon subarray consisting of 7 individual antennas, and $11^{\circ}$ for a combination of 7 adjacent hexagonal subarrays ("anemone" antenna patch).

Each antenna is connected to its own transceiver with independent phase control and a scalable output up to $2 \mathrm{~kW}$. This arrangement allows very high flexibility of beam form- ing and beam steering with a symmetric radar beam and arbitrary beam pointing directions. The transceivers are accommodated in six 20 -ft office containers located in equal distance at the perimeter of the antenna array. The transceivers are state of the art VHF solid state pulsed transmitters and down converters with widely programmable operating parameters, such as frequency, phase and amplitude. The innovative design incorporates vector RF detection circuitry allowing continuous monitoring of output power, phase and load impedance on a pulse-to-pulse basis. The radar hardware is designed and manufactured by Genesis Software Pty Ltd.

On reception the IF signals from each of the 7 transceivers, each connected to 7 antennas arranged in a hexagon structure as shown in Fig. 1, are combined to 55 receiving channels. The IF signals from each of the 8 transceivers, each connected to 8 antennas located in asymmetric patches at the perimeter of the array are combined to further 6 receiving channels. The combined 61 IF signals are led by coaxial cables of equal length to the data acquisition hardware in the nearby located radar control house. In the first expansion 


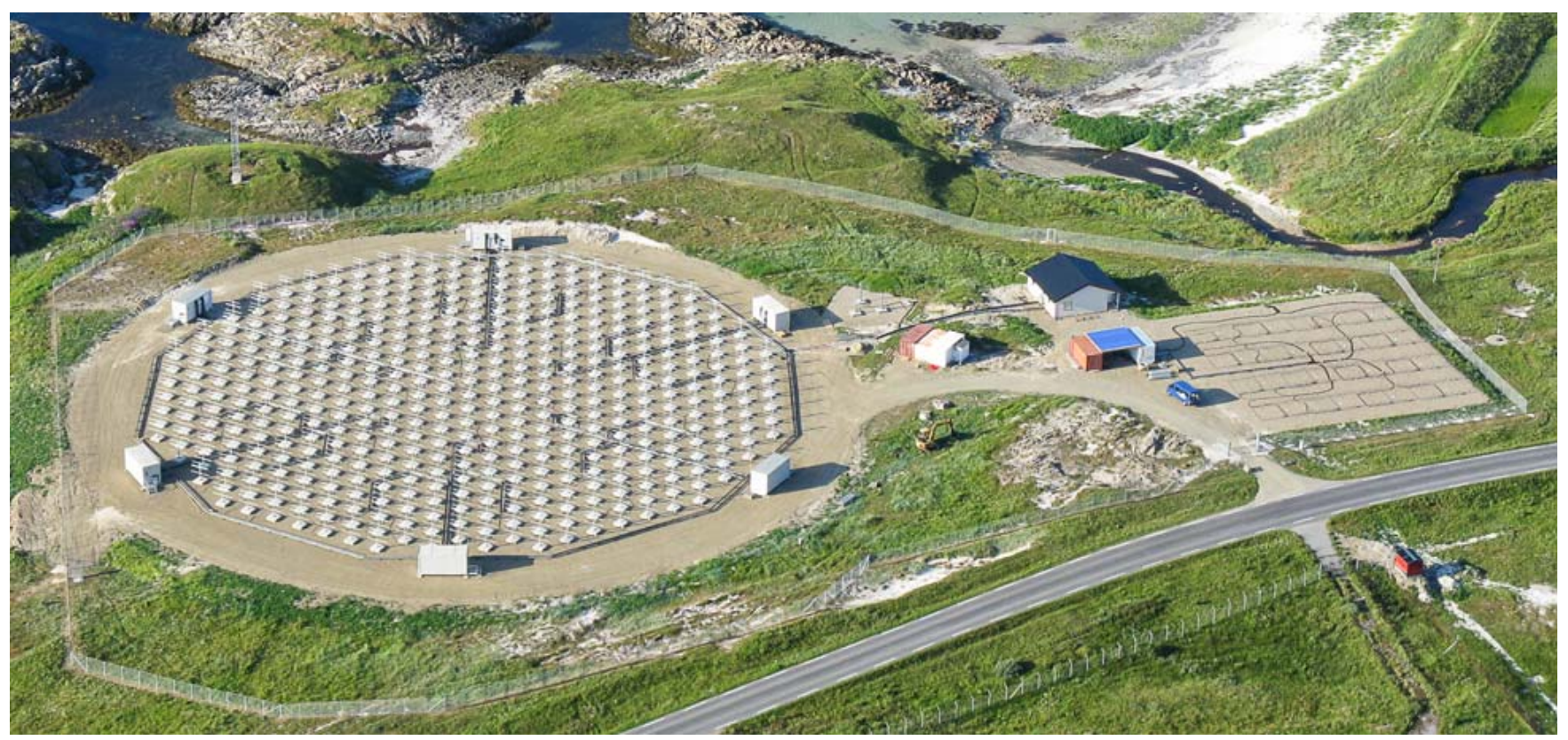

Fig. 4. View of the MAARSY site after completion of the main antenna array in August 2009. The 433 Yagi antennas are connected by cables of equal length to sockets at the wall of the 6 containers at the perimeter of the array. Up to $42 \mathrm{~km}$ of low loss coaxial cable have been laid. The small antenna array on the right hand site of the photograph is used for reception with the ALWIN64 interim system. Photo: Toralf Renkwitz.

stage the radar will have 16 baseband receivers and 32 digitizers for the corresponding numbers of I and Q channels only. Therefore controllable multifunction combiners will be used to either combine the IF signals of 7 adjacent hexagonal antenna substructures ("anemone" antenna patch) or select one of them as input of the 16 base band converters. Overall 9 multifunction combiners will be in use to connect the IF signals of 7 anemone patches, 6 single hexagons, and 6 remaining antenna patches along the perimeter of the array to the 16 base band receivers as shown in Fig. 3. These combining units allows a wide range of receiving arrangements with different antenna configurations for interferometric or multi-receiver applications. Additionally a 16 channel antenna interface unit with down conversion to IF is used to feed 16 additional RF signals from separate receiving antennas used for e.g. interferometer observations of meteors or for boundary layer observations.

A second output of the multifunction combiner will provide the 9 combined signals to a 9-to- 1 combiner whose output is permanently connected to base band receiver one. This receiving setup in combination with the 433 phased controlled transmitters will be used for classical Doppler beam swinging. It will remain in the new VHF system also after an upgrade to 61 analog or digital receiving channels.

The individual phase control of each transceiver module allows also multiple beam operations. During the first expansion stage of the radar the maximum number of separated beams is limited to 7 due to the number of available detec-

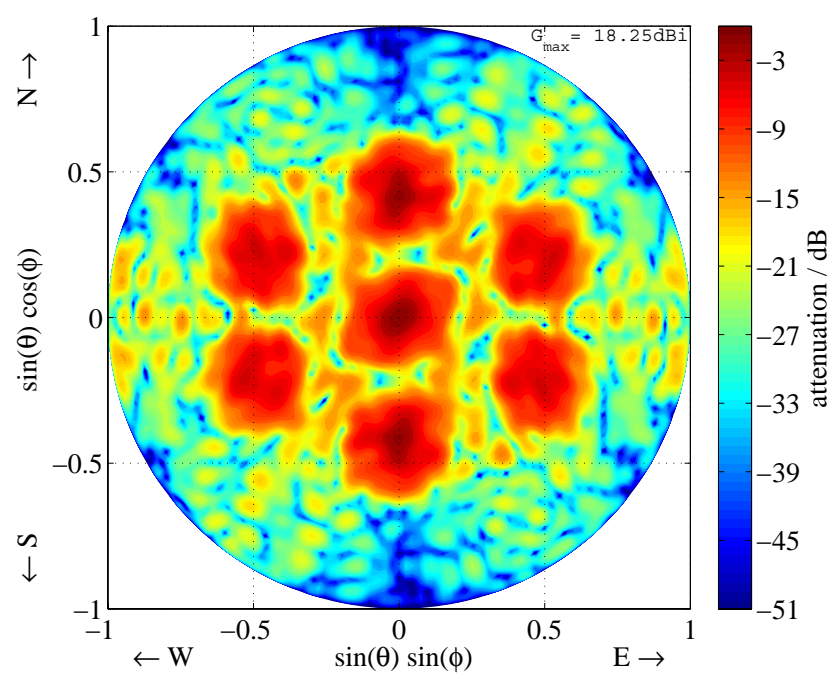

Fig. 5. Model results of the antenna radiation pattern for a 7-beam configuration of MAARSY. 

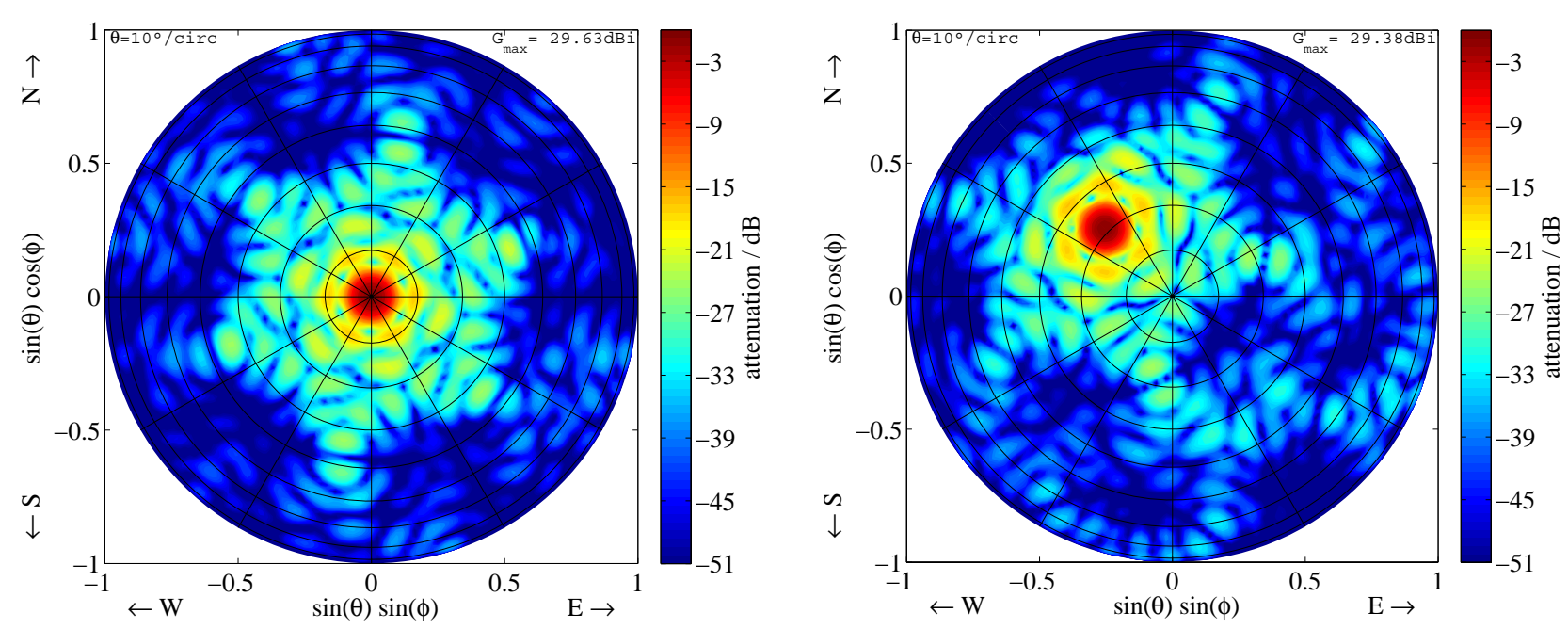

Fig. 7. Computed radiation pattern for the antenna of the initial expansion stage of MAARSY for a beam pointed to zenith (left) and tilted to $21^{\circ}$ to the NW direction (right). The Numerical Electromagnetics Code (NEC) with the Norton-Sommerfeld approximation was used, making allowance for the imperfect ground at the location.

tion channels and the associated "anemone" antenna patches. Figure 5 shows the computed antenna radiation pattern for such a multiple beam configuration formed by the anemones shown in Fig. 3.

\section{Interim solution and installation schedule}

The installation of MAARSY started in September 2008 with the dismantling of the antenna array of the old ALWIN radar. Parts of the antenna array and the container housing the transmitter and receiving units were moved approximately $100 \mathrm{~m}$ westward of the site to a new leveled area. This interims solution called ALWIN64 uses six of the newly designed antennas arranged as three crossed Yagis in an equilateral triangle with $4 \mathrm{~m}$ spacing for transmission and 64 of the old Yagi antennas arranged in a 8-by-8 array for reception. 16 subgroups of 4 combined antennas are connected to the new 16 channel receiving and data acquisition unit via an antenna interface unit. Even though the ALWIN64 radar is less sensitive compared to the old ALWIN radar due to the smaller number of antennas for transmission as well as for reception it was possible to detect Polar Mesosphere Summer Echoes in 2009 and continue the serious of more than 14 years of PMSE observation at Andenes.

The 64-antenna array will stay at the site also after completion of the new system to be used for multi-beam reception in combination with the main array. A Butler matrix was designed to form 16 beams in hardware (Renkwitz et al., 2009), while the main array is generating an uniform illumination with a broad beam. The 16 beams with a beam width of approximately $9^{\circ}$ can also be generated in software to compare

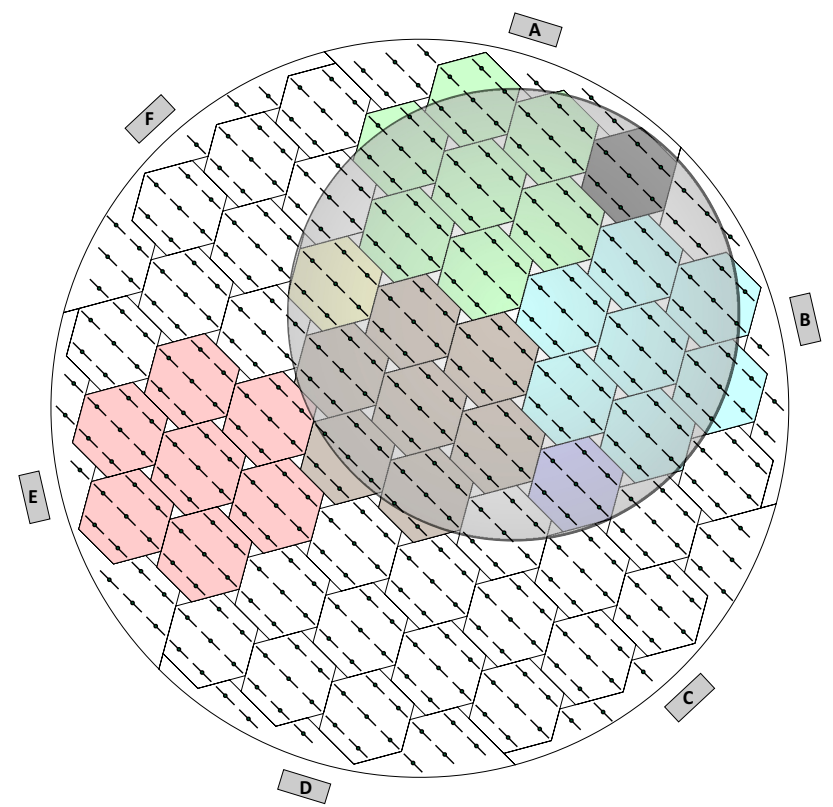

Fig. 6. Initial expansion stage of MAARSY as scheduled for spring 2010. The antennas connected to transceiver modules are highlighted in color. Four anemone antenna patches and three additional hexagons will allow various setups for multi-receiver observation. The circle marks the hexagons to be used to form a central symmetric antenna beam with a half power beam width of $5.8^{\circ}$ for classical Doppler beam steering. 
the results of digital and analog beam forming as performed by the Butler matrix.

The installation of the antenna array and the laying of the RF cables between the 433 antennas and the six containers accommodating the transceivers as well as the $61 \mathrm{IF}$ cables from the containers to the radar control house was completed in August 2009. Figure 4 shows a photograph of the MAARSY site during end of the installation in August 2009. The receive antenna array of ALWIN64 interim system is located on the squared leveled area on the right hand site of the photograph.

The radar control and data acquisition hardware as well as 217 transceiver modules will be installed in Spring 2010. The initial expansion stage will use 31 hexagons of the array as marked in Fig. 6. The close located green, brown and blue anemone antenna groups together with additional 3 hexagons form an symmetric antenna radiation pattern. The antenna beam width of about $5.8^{\circ}$ will be comparable to the old ALWIN system (Latteck et al., 1999) but with symmetrical sidelobes. Figure 7 shows the computed antenna radiation patterns of the initial expansion stage of the new VHF radar for a beam pointed to zenith and tilted to $21^{\circ}$ to the NW direction. The full extension of MAARSY is scheduled for spring 2011 with the goal to observe the 2011 PMSE season with full power.
Acknowledgements. The authors would like to thank IAP personal who worked hard with the installation MAARSY in particular Jörg Trautner, Thomas Barth, Jens Wedrich, Norbert Engler, Dieter Keuer, Marius Zecha, Hans-Jürgen Heckl, Torsten Köpnick, Manja Placke, and Qiang Li, as well as the students Ding Tao, Gunnar Keuer, Christian Schernus, Sophie Latteck, Danilo Hauch and Richard Hünerjäger. We are indebted to the staff of the Andøya Rocket Range for their permanent support. The radar development was supported by grant 01 LP 0802A of Bundesmisterium für Bildung und Forschung. Topical Editor M. Förster thanks E. Fürst and M. Rietveld for their help in evaluating this paper.

\section{References}

Latteck, R., Singer, W., and Bardey, H.: The ALWIN MST radar Technical design and performances, in: Proceedings of the 14th ESA Symposium on European Rocket and Balloon Programmes and Related Research, Potsdam, Germany (ESA SP-437), edited by Kaldeich-Schürmann, B., 179-184, 1999.

Renkwitz, T., Singer, W., and Latteck, R.: Study of multibeam ability for the VHF MST ALWIN radar system, in: Proceedings of the 12th International Workshop on Technical and Scientific Aspects of MST Radar (MST12), 17-23 May 2009, London/Ontario, Canada, submitted, 2009.

Singer, W., Keuer, D., Hoffmann, P., Czechowsky, P., and Schmidt, G.: The ALOMAR SOUSY radar: Technical design and further developments, in: Proceedings of the 12th ESA Symposium on European Rocket and Balloon Programmes and Related Research, Lillehammer, Norway (ESA SP-370), 409-415, 1995. 